\title{
Focal and Osteosclerotic Bone Diseases
}

\author{
Stuart H. Ralston ${ }^{1}\left(\mathbb{D} \cdot\right.$ Rene Rizzoli $^{2}$
}

Received: 9 April 2019 / Accepted: 19 April 2019 / Published online: 9 May 2019

(c) Springer Science+Business Media, LLC, part of Springer Nature 2019

It is our great pleasure to devote the May 2019 issue of Calcified Tissue International to the topic of Focal and Osteosclerotic bone diseases. These conditions have a strong genetic component but until recently, the mechanisms which determine where and when lesions occur have been unclear. Advances in understanding the molecular basis of these disorders are set to change that, and in fact, already have done so in the case of Melorheostosis, leading to new avenues for therapeutic intervention.

The special issue begins with an authoritative review on classical Paget's disease of bone (PDB) by Luigi Gennari and colleagues [1]. This article not only provides an overview of the tremendous leaps that have been made in understanding genetic mechanisms of PDB and giant cell tumour of bone but also revisits the enigma of which environmental factors influence the disease and how they interact with predisposing genetic variants to do so. Finally, Gennari and colleagues review the latest developments in the management of PDB including the recently published clinical guidelines on diagnosis and management of the condition [2]. This article is followed by a review of rare inherited syndromes which show clinical overlap with PDB including familial expansile osteolysis, Juvenile PDB and the multisystem proteinopathy (MSP) syndromes [3]. Particular attention is paid to the advances that have been made in understanding the pathophysiology of MSP syndromes. The first MSP to be identified was named inclusion body myopathy, Paget's disease and front-temporal dementia (IBMPFD) based on the clinical manifestations of the disorder. This syndrome was found to be due to mutations in $V C P$ by linkage analysis

Stuart H. Ralston

stuart.ralston@ed.ac.uk

Rene Rizzoli

Rene.Rizzoli@unige.ch

1 Centre for Genomic and Experimental Medicine, University of Edinburgh, Edinburgh EH4 2XU, UK

2 Division of Bone Diseases, Geneva University Hospitals, 1211 Geneva 14, Switzerland and positional cloning [4], but it soon became apparent that the disorder was genetically heterogeneous implying that other genes and pathways may also be involved. Genome sequencing identified mutations in HNRNAPAl and HNRN$P A 2 B 1$ as another cause of the syndrome with an extended phenotype encompassing amyotrophic lateral sclerosis in some patients [5]. These observations linked abnormalities of protein degradation and formation of protein aggregates with the development of intracellular inclusion bodies leading to disordered cellular function of brain, muscle and bone. It has also become clear that mutations in SQSTMI and $O P T N$ which are both implicated in classical PDB may also cause MSP-mediated neurological dysfunction in the absence of PDB. The precise mechanisms that determine why a single genotype can lead to such diverse phenotypes are incompletely understood but may involve inheritance of interacting genetic variants that determine whether the target tissue is muscle, brain or bone [6,7].

Next, Hartley and colleagues provide a detailed bench-tobedside review of fibrous dysplasia and McCune-Albright syndrome [8]. The review covers all aspects of these conditions from their genetic basis and pathophysiology, through to the clinical features and management options. This is a tour-de-force from the leading researchers in the field and recommended reading for anyone who is involved in the treatment of these diseases. The elegant review by Wordsworth and Chan on Melorheostosis and Osteopoikilosis [9] also makes fascinating reading. The authors provide a detailed review of the latest advances in understanding these rare conditions, most notably the recent discovery of somatic MAP2K1 mutations in Melorheostosis. In addition, the authors provide a fascinating insight into the management of these disorders based on their extensive personal experience. There then follows a comprehensive review by Buch and colleagues of the enigmatic syndrome of chronic non-bacterial osteomyelitis (CNO) [10]. This rare disorder presents with bone pain and deformity secondary to focal abnormalities of increased bone turnover. It shares some similarities with PDB but affects much younger people and seems to have a distinct pathogenic basis. The condition is 
suspected to have a genetic basis but so far, no pathogenic mutations have been found in affected individuals. There is good evidence for dysregulated cytokine production but why this occurs is unclear. Further research is awaited to determine the cause of $\mathrm{CNO}$, but perhaps it may represent another focal bone disorder where somatic mutations are operative?

The review of Camurati-Engelman disease by Van Hul and colleagues [11], provides a timely update on the pathogenesis and management of this rare disease caused by mutations of the TGFBl gene, which prevent the so-called LAP region of the protein binding to the mature TGF $\beta 1$ peptide thereby causing activation of TGF $\beta 1$ signaling. As the authors explain, corticosteroid therapy seems to be the only effective treatment for this condition at present, but there is some hope that the promising results that have been achieved with TGF receptor antagonists in animal models might eventually be translated into clinical practice. The final review in the special issue by Bhadada and colleagues concerns Fibrogenesis Imperfecta Ossium (FIO) [12]. This extremely rare disorder is characterised by the laying down of abnormal collagen fibrils in bone with defective mineralisation of bone matrix and the pathogenesis has puzzled clinicians for decades. The condition may be associated with paraprotein production and a genetic basis has been suspected by the finding of a positive family history in some patients. The cause of the condition remains unclear. Management of these patients has always proved difficult, but Bhadada have reported very promising results with growth hormone treatment in a case series of their own patients which hopefully will be replicated by others.

\section{Compliance with Ethical Standards}

Conflict of interest Stuart H. Ralston and Rene Rizzoli have no conflicts of interest to declare.

Human and Animal Rights and Informed Consent Not applicable.

\section{References}

1. Gennari L, Rendina D, Falchetti A, Merlotti D (2019) Paget's disease of bone. Calcif Tissue Int. 104(5):483-500

2. Ralston SH, Corral-Gudino L, Cooper C, Francis RM, Fraser WD, Gennari L et al (2019) Diagnosis and management of Paget's disease of bone in adults: a clinical guideline. J Bone Miner Res 34(4):579-604

3. Ralston SH, Taylor JP (2019) Rare inherited forms of Paget's disease and related syndromes. Calcif Tissue Int. 104(5):501-516

4. Watts GD, Wymer J, Kovach MJ, Mehta SG, Mumm S, Darvish D et al (2004) Inclusion body myopathy associated with Paget disease of bone and frontotemporal dementia is caused by mutant valosin-containing protein. Nat Genet 36(4):377-381

5. Kim HJ, Kim NC, Wang YD, Scarborough EA, Moore J, Diaz $\mathrm{Z}$ et al (2013) Mutations in prion-like domains in hnRNPA2B1 and hnRNPA1 cause multisystem proteinopathy and ALS. Nature 495(7442):467-473

6. Lee Y, Jonson PH, Sarparanta J, Palmio J, Sarkar M, Vihola A et al (2018) TIA1 variant drives myodegeneration in multisystem proteinopathy with SQSTM1 mutations. J Clin Invest 128(3):1164-1177

7. Mehta SG, Watts GD, Adamson JL, Hutton M, Umberger G, Xiong $S$ et al (2007) APOE is a potential modifier gene in an autosomal dominant form of frontotemporal dementia (IBMPFD). Genet Med 9(1):9-13

8. Hartley I, Zhadina M, Collins MT, Boyce A (2019) Fibrous dysplasia of bone and McCune-Albright syndrome: a bench to bedside review. Calcif Tissue Int 104(5):517-529

9. Wordsworth P, Chan M (2019) Melorheostosis and osteopoikilosis: a review of clinical features and pathogenesis. Calcif Tissue Int 104(5):530-543

10. Buch K, Thuesen ACB, Brons C, Schwarz P (2018) Chronic non-bacterial osteomyelitis: a review. Calcif Tissue Int. 104(5):544-553

11. Van Hul W, Boudin E, Vanhoenacker FM, Mortier G (2019) Camurati-Engelmann disease. Calcif Tissue Int. 104(5):554-560

12. Bhadada SK, Dhaliwal R, Dhiman V, Rao SD (2019) Fibrogenesis imperfecta ossium. Calcif Tissue Int 104(5):561-569

Publisher's Note Springer Nature remains neutral with regard to jurisdictional claims in published maps and institutional affiliations. 